\title{
B-Galactosidase II Activity in Relation to Changes in Cell Wall Galactosyl Composition during Tomato Ripening
}

\author{
C.M. Sean Carrington ${ }^{1}$ and Russell Pressey ${ }^{2}$ \\ Richard B. Russell Agricultural Research Center, U.S. Department of Agriculture, Agricultural Research \\ Service, P. O. Box 5677, Athens, GA 30613 \\ Additional index words. Lycopersicon esculentum, B-galactosidase, fruit softening
}

\begin{abstract}
Activity of B-galactosidase II (EC 3.2.1.23), which can hydrolyze B-galactan from tomato cell walls, increased markedly during ripening of 'Roma' and 'Rutgers' tomatoes (Lycopersicon esculentum Mill.). Activity of two other Bgalactosidase isozymes, incapable of galactan hydrolysis, was present in green fruit and remained unchanged throughout ripening. B-Galactosidase II activity was not detectable in green fruit of either cultivar, appearing first at the breaker stage of 'Roma' fruit and not until the pink stage of 'Rutgers' fruit. Consistent with this, galactose loss from $\mathrm{Na}_{2} \mathrm{CO}_{3}$-soluble pectin (NSP) was detectable at an earlier stage in 'Roma' vs. 'Rutgers' fruit. A greater decline in NSP galactose was evident in 'Roma' fruit compared to 'Rutgers' fruit, in keeping with the higher levels and longer period of B-galactosidase II expression in the former. Significant galactose loss from trans -1,2-diaminocyclohexane- $N, N, N^{\prime}, N^{\prime}$-tetraacetic acidsoluble pectin, in contrast, was not seen until the last stage of ripening. These results indicate that the long-reported, net galactosyl loss from the cell walls of ripening tomatoes correlates with B-galactosidase II activity. Nonetheless, the observation that softening commenced before B-galactosidase II activity or galactose loss was detectable suggests some other basis for the earliest stages of ripening-related fruit softening in tomato.
\end{abstract}

Tomato has become a model system for the study of fruit ripening and, more particularly, the changes that bring about fruit softening (Brady, 1987; Fischer and Bennett, 199 1). In this fruit, despite some results implicating the hemicellulosic and cellulosic cell wall fractions in fruit softening (e.g., Maclachlan and Brady, 1994), most recent work has focused on the pectic fractions. In particular, there has been much interest in the polyuronide-solubilizing enzyme, polygalacturonase (PG; EC 3.2.1.15). Its activity rises dramatically during ripening, and a close correlation between PG and pericarp softening has been demonstrated in a range of tomato cultivars (Ahrens and Huber, 1990). More recent work, however, has made it clear that PG cannot be the rate-limiting enzyme in tomato softening. Blocking PG expression by transformation with the antisense gene for PG does not prevent fruit softening (Schuch et al., 1991; Smith et al., 1988) or only partially (Barrington et al., 1993; Kramer et al., 1992). Moreover, genetically engineered expression of PG in the rin tomato mutant, which does not ripen and which normally lacks PG, does not restore fruit softening (Giovannoni et al., 1989).

An alternative to PG, as the enzyme responsible for fruit softening", is clearly needed. In tomato, pectin methyl esterase has been viewed as an accessory to PG action (Pressey and Avants, 1982), and antisense inhibition of its expression has shown no effect on ripening-related softening, although this did accelerate the tissue disintegration associated with over-ripening (Tieman and Handa, 1994). Other possible pectic enzymes have been studied less although the changes they catalyze have been documented well. Most notable of the latter is a decline in certain neutral

Received for publication 18 May 1995. Accepted for publication 19 Sept. 1995. This work was supported in part by the award of a Fulbright Fellowship to C.M.S.C. We thank Jimmy K. Avants for expert technical assistance. The cost of publishing this paper was defrayed in part by the payment of page charges, Under postal regulations, this paper therefore must be hereby marked advertisement solely to indicate this fact.

'Senior lecturer, Biology Dept., Univ. of the West Indies, P.O. Box 64, Bridgetown, Barbados.

${ }^{2}$ Research chemist. sugars, especially galactose (Gross, 1984; Gross and Wanner, 1979; Kim et al., 1991; Seymour et al., 1990; Wanner and Bloom, 1977), an observation also made in other ripening fruit (Brady, 1987). This galactose loss is diminished where softening is reduced, such as following heat treatment (Mitcham and McDonald, 1992) or in the rin and nor ripening mutants (Gross, 1984; Kim et al., 199 1). Furthermore, the common cell wall compositional change shown by ripening tomatoes with the anti sense PG gene and control fruit, both of which soften substantially, is a marked loss of pectic galactan (Barrington et al., 1 993). Some time ago, an enzyme capable of catalyzing this decline, ß-galactosidase II, one of three $\beta$-galactosidase isozymes in tomato, was characterized (Pressey, 1983). As a first step in assessing the role of ß-galactosidase II in tomato softening, this paper examines in detail the timing of appearance of this enzyme in two tomato cultivars and correlates this with the net loss of galactosyl residues from the cell wall during ripening.

\section{Materials and Methods}

Plant material. Field-grown 'Roma' and 'Rutgers' tomatoes were harvested at six ripeness stages (U.S. Dept. of Agriculture, 1976)—mature green, breaker, turning, pink, light red, and red. Pericarp tissue, cut into segments of about $1 \mathrm{~cm}^{3}$, was used directly for enzyme extraction, while portions for cell wall analysis were stored at $-20 \mathrm{C}$ until used.

Using a Magness-Taylor pressure tester with 6.9-mm tip, fruit firmness was measured at three locations along the equatorial diameter of three representative fruit of both cultivars and all six ripeness stages. Based on the previous work of Kader et al. (1978), skin removal was deemed unnecessary.

$\beta$-Galactosidase extraction and assay. Triplicate $100-\mathrm{g}$ samples of pericarp tissue from all six ripeness stages of both cultivars were each homogenized in $100 \mathrm{ml}$ of $1 \mathrm{M} \mathrm{NaCl}$ using a Polytron, and the $\mathrm{pH}$ was adjusted to 6 . Homogenates were stirred for 30 rein, centrifuged at $8000 \times \mathrm{g}$ for 30 rein, and $\left(\mathrm{NH}_{4}\right)_{2} \mathrm{SO}_{4}$ added to each supernatant to $80 \%$ of saturation. The precipitated proteins were 
collected by centrifugation, dissolved in $20 \mathrm{ml}$ of $0.15 \mathrm{M} \mathrm{NaCl}$, and dialyzed against the same overnight. The dialysates were then centrifuged to remove trace amounts of insoluble material. All of the above steps were carried out at 4C. Aliquots of each extract were chromatographed on a Mono S column in a FPLC system (Pharmacia) using $30 \mathrm{ml}$ of a linear gradient of 0 to $0.5 \mathrm{M} \mathrm{NaCl}$ in $0.02 \mathrm{M} \mathrm{NaOAc}, \mathrm{pH} 4$.75. Fractions were assayed for $\beta$-galactosidase activity using p-nitrophenyl- $\beta-D$-galactopyranoside (Pressey, 1983).

Cell wall analysis. Cell wall material (CWM) was prepared from triplicate 15-g portions of pericarp tissue from all six ripeness stages of both cultivars. Tissue was placed in boiling $95 \%$ ethanol for $10 \mathrm{~min}$ and homogenized with a Polytron when cool, and the insoluble material was washed with acetone and then air-dried (Barrington et al., 1993). Sequential extraction of this CWM with $0.01 \% \mathrm{NaN}_{3}(4 \mathrm{~h}), 0.05 \mathrm{~m}$ CDTA in $0.05 \mathrm{~m} \mathrm{NaOAc}, \mathrm{pH} 6$ (overnight), and $0.1 \mathrm{M} \mathrm{Na}_{2} \mathrm{CO}_{3}$ containing $1 \mathrm{mg} \cdot \mathrm{ml}^{-1} \mathrm{NaBH}_{4}$ (overnight), gave rise to water-soluble pectin (WSP), CDTAsoluble pectin (CSP), and $\mathrm{Na}_{2} \mathrm{CO}_{3}$-soluble pectin (NSP) fractions, respectively. Extracts were dialyzed for 2 days at $4 \mathrm{C}$ against distilled $\mathrm{H}_{2} \mathrm{O}$, and the volume of each dialysate was recorded. Aliquots of each fraction were assayed for neutral carbohydrate by the anthrone method (Dische, 1962) and for uronide by the mhydroxydiphenyl method (Blumenkrantz and Asboe-Hansen, 1973). A further aliquot was freeze-dried, and polysaccharides were hydrolyzed with $2 \mathrm{~N}$ TFA for $1 \mathrm{~h}$ at $121 \mathrm{C}$. The resulting monosaccharides were then converted to alditol acetates (Blakeney

Fig. 1. Representative elution profile of B-galactosidase activity of ripe 'Roma' tomatoes. Extract was chromatographed on a Mono $\mathrm{S}$ column in $20 \mathrm{~mm} \mathrm{NaOAc}, \mathrm{pH} 4.75$, using a $30-\mathrm{ml}, 0$ to $0.5 \mathrm{~m} \mathrm{NaCl}$ linear gradient, beginning at fraction 2 . One unit of enzyme activity was defined as the amount that hydrolysed $1 \mu \mathrm{mol}$ of $p$-nitrophenyl- $\beta-D$-galactopyranoside in $1 \mathrm{~h}$ at $37 \mathrm{C}$. Peak $\mathrm{I}+\mathrm{III}=\beta$-galactosidases $\mathrm{I}+\mathrm{III}$. Peak $\mathrm{H}=\beta$ galactosidase II.

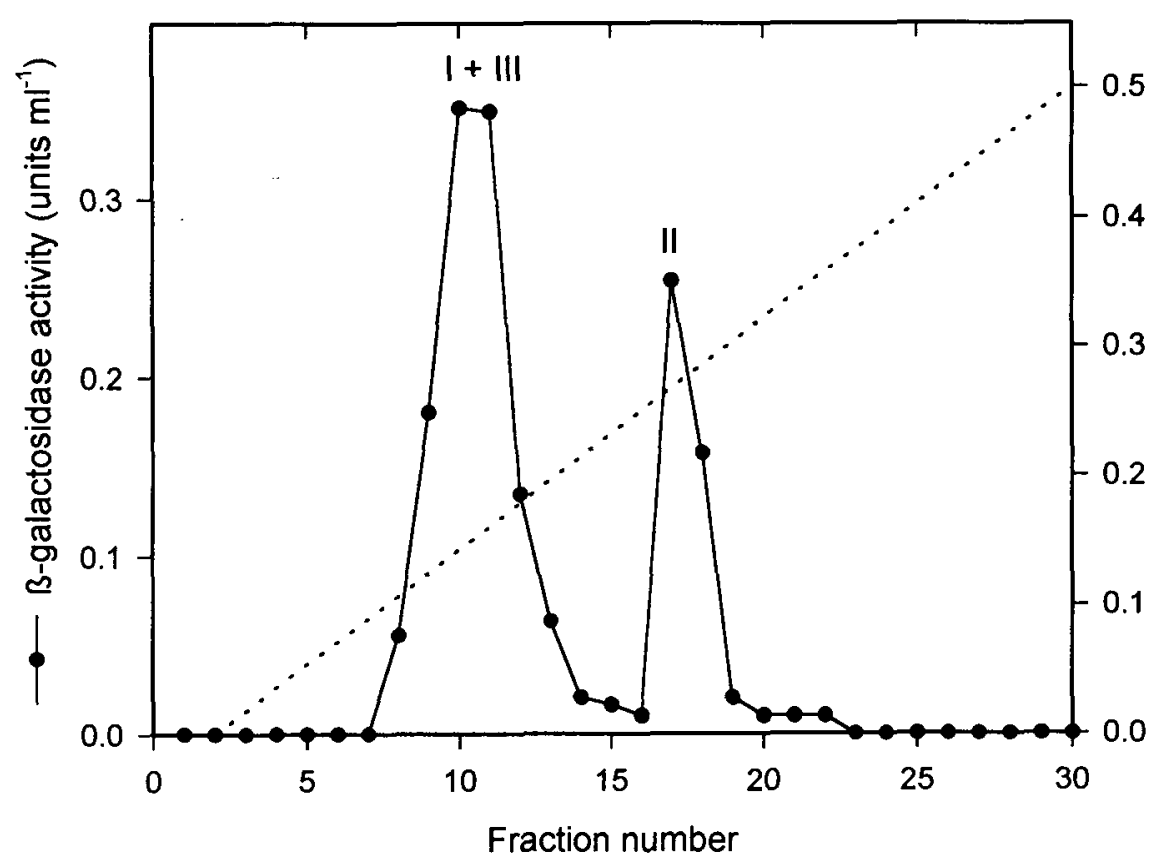

et al., 1983) and analyzed isothermally at 220C using a Perkin-Elmer 3920B gas chromatography with a flame ionization detector, fitted with a $3 \%$ SP-2340 on Supelcoport 100/120 packed column $(1.5 \mathrm{~m}$ $\times 2 \mathrm{~mm}$ i.d.). Integration was provided by a Hewlett-Packard HP3396A integrator.

\section{Results}

$\beta$-Galactosidase activities and fruit firmness. Extracts of tomatoes are known to contain at least three isozymes of B-galactosidase, which can be separated by a two-step procedure consisting of chromatography on DEAE-Sephadex A-50 and gel filtration on Sephadex G- 100 (Pressey, 1983). In the present study, ß-galactosidase II was separated from the other isozymes in a single step by ion-exchange chromatography on a Mono $\mathrm{S}$ column in a FPLC system (Fig. 1). By chromatographing B-galactosidases as described by Pressey (1983), it was found that the first peak of activity consisted of $\beta$-galactosidases I and III and the second peak was due to $ß$-galactosidase II.

In 'Roma' and 'Rutgers' tomatoes, combined $\beta$-galactosidase I and III activity was present in the mature green fruit and remained essentially unchanged during ripening (Table 1 ). In contrast, $\beta$ galactosidase II was not detected in green fruit of either cultivar. BGalactosidase II activity increased steadily as ripening progressed, the enzyme activity being detected in 'Roma' fruit at the breaker stage but not until the pink stage in 'Rutgers' fruit. In both cultivars, $\beta$-galactosidase II increased 6- to 7-fold, relative to the first detectable activity.

Firmness measured in the fruit using a simple penetrometer showed that the extent of softening was similar in the two cultivars, firmness of red fruit being about $30 \%$ that of green fruit (Table 1 ). In terms of the timing and rate of ripening in the two cultivars, softening of the 'Rutgers' fruit appeared to lag slightly behind that of the 'Roma' fruit.

Cell wall changes accompanying ripening. As ripening progressed in both cultivars, there was an increase in WSP, whether measured as uronide or neutral carbohydrate (Figs. 2 and 3). There were no significant changes in CSP but NSP declined during ripening, mirroring the increase seen in the WSP (Figs. 2 and 3). The amounts of WSP and CSP were significantly higher in 'Rutgers' than 'Roma' tomatoes at corresponding stages of ripeness, whereas the levels of NSP were quite similar in the two cultivars.

In the NSP fraction, galactose was the most prominent neutral sugar, followed by arabinose then rhamnose (Fig. 4), while xylose, mannose, and glucose were present in relatively minor amounts, the latter showing no net change during ripening (data not shown). In 'Roma' fruit, galactose in the NSP fraction decreased as early as the breaker stage, dropping markedly at the turning/pink and light $\mathrm{red} /$ red transitions (Fig. 4). Arabinose and rhamnose mobilization was similar to that of galactose except that the magnitude of the galactose decline was much greater. Galactose in red fruit fell to $8 \%$ the level found in green fruit, while arabinose and rhamnose only declined to $33 \%$ the green fruit level. In contrast, in 'Rutgers' fruit, there was no significant drop in galactose in the NSP fraction until fruit 
Table 1. Combined activity of ß-galactosidases I + III, activity of ß-galactosidase II, and firmness of 'Roma' and 'Rutgers' tomatoes at six ripeness stages (mean of three replicates $\pm \mathrm{SD}$ ).

\begin{tabular}{|c|c|c|c|c|c|c|}
\hline \multirow[b]{2}{*}{ Stage $^{z}$} & \multicolumn{3}{|c|}{ Roma } & \multicolumn{3}{|c|}{ Rutgers } \\
\hline & $\begin{array}{l}\text { Firmness } \\
(\mathrm{N})\end{array}$ & $\begin{array}{l}\text { ß-galactosidases I + III } \\
\left(\mu \mathrm{mol} \cdot \mathrm{h}^{-1} \cdot \mathrm{g}^{-1} \text { fresh wt }\right)\end{array}$ & $\begin{array}{c}\text { (ß-galactosidase II } \\
\left(\mu \mathrm{mol} \cdot \mathrm{h}^{-1} \cdot \mathrm{g}^{-1} \text { fresh } \mathrm{wt}\right)\end{array}$ & $\begin{array}{l}\text { Firmness } \\
(\mathrm{N})\end{array}$ & $\begin{array}{l}\text { B-galactosidases I + III } \\
\left(\mu \mathrm{mol} \cdot \mathrm{h}^{-1} \cdot \mathrm{g}^{-1} \text { fresh } \mathrm{wt}\right)\end{array}$ & $\begin{array}{c}\text { B-galactosidase II } \\
\left(\mu \mathrm{mol} \cdot \mathrm{h}^{-1} \cdot \mathrm{g}^{-1} \text { fresh } \mathrm{wt}\right)\end{array}$ \\
\hline$\overline{\mathrm{G}}$ & $74.3 \pm 5.0$ & $1.28 \pm 0.09$ & $\mathrm{n} \mathrm{d}^{\mathrm{y}}$ & $69.0 \pm 2.1$ & $1.06 \pm 0.06$ & nd \\
\hline B & $60.4 \pm 1.0$ & $1.53 \pm 0.06$ & $0.07 \pm 0.01$ & $60.9 \pm 4.1$ & $1.21 \pm 0.15$ & nd \\
\hline $\mathrm{T}$ & $53.8 \pm 4.7$ & $1.58 \pm 0.42$ & $0.21 \pm 0.11$ & $57.0 \pm 5.1$ & $1.14 \pm 0.22$ & $0.07 \pm 0.01$ \\
\hline $\mathrm{P}$ & $47.4 \pm 5.2$ & $1.52 \pm 0.25$ & $0.22 \pm 0.02$ & $50.0 \pm 8.7$ & $0.90 \pm 0.08$ & $0.10 \pm 0.04$ \\
\hline $\mathrm{L}$ & $31.6 \pm 0.9$ & $1.44 \pm 0.07$ & $0.28 \pm 0.05$ & $24.3 \pm 0.4$ & $0.84 \pm 0.06$ & $0.27 \pm 0.03$ \\
\hline $\mathrm{R}$ & $23.5 \pm 3.3$ & $1.43 \pm 0.09$ & $0.51 \pm 0.04$ & $20.4 \pm 4.6$ & $1.11 \pm 0.14$ & $0.44 \pm 0.09$ \\
\hline
\end{tabular}

${ }^{\mathrm{T}} \mathrm{G}=$ mature green; $\mathrm{B}=$ breaker; $\mathrm{T}=$ turning; $\mathrm{P}=$ pink; $\mathrm{L}=$ light red; $\mathrm{R}=$ red.

yd $=$ not detectable, where threshold of detection $=0.03 \mu \mathrm{mol} \cdot \mathrm{h}^{-1} \cdot \mathrm{g}^{-1}$ fresh weight.

reached the pink stage (Fig. 4). The declines in arabinose and rhamnose followed the pattern seen for galactose (Fig. 4) but, as for 'Roma', the fall in galactose (to $14 \%$ the green level) was much more acute than for these two sugars (to $50 \%$ the green level).

In the CSP fraction, by the red stage, galactose declined to about half the level found in green fruit (Fig. 5). Mean values suggest that this decline began earlier, especially in 'Roma' fruit, but it is only at the last stage that this drop is significant. As for the NSP fraction, the minor constituent monosaccharides, xylose, mannose, and glucose, as well as the more abundant rhamnose and arabinose, were present but there was no net significant change in these during ripening (data not shown).

\section{Discussion}

The uronide and neutral carbohydrate composition of the various pectin fractions (Figs. 2 and 3) confirm that tomato softening is characterized by no gross change in CSP but a transformation of relatively insoluble NSP to readily soluble WSP, an event largely catalyzed by PG (Barrington et al., 1993).

No ß-galactosidase II activity was detected in green fruit, contrary to previous results (Pressey, 1983) and those recently reported by Carey et al. (1995). This may reflect the different cultivars used or the difference in methodology. The extraction procedure of all the studies is essentially the same, but a one-step

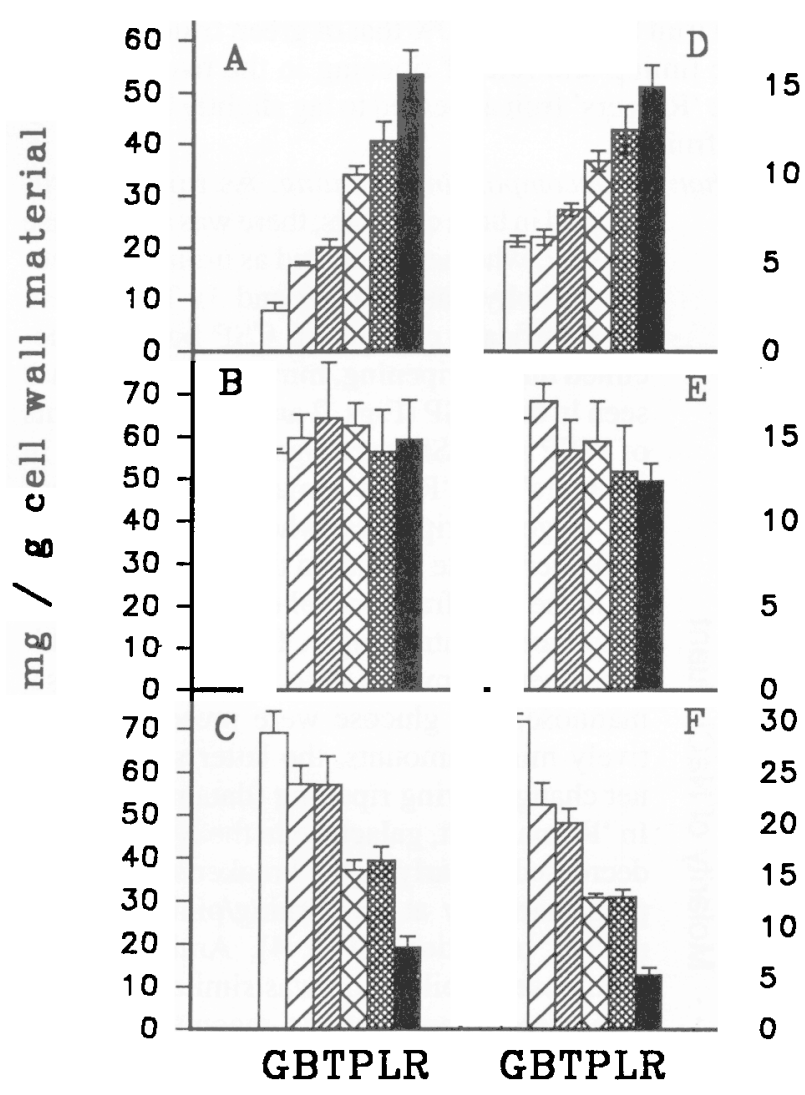

Fig. 2. Quantities of uronide (A-C) and neutral carbohydrate (D-F) solubilized from cell walls of 'Roma' tomatoes at six ripeness stages by water (A and $\mathbf{D}), 0.05$ M CDTA ( $\mathbf{B}$ and $\mathbf{E})$, and $0.1 \mathrm{M} \mathrm{Na}_{2} \mathrm{CO}_{3}(\mathbf{C}$ and $\mathbf{F})$. Mean of three replicates \pm SD. $\mathrm{G}=$ mature green; $\mathrm{B}=$ breaker; $\mathrm{T}=$ turning; $\mathrm{P}=$ pink $\mathrm{L}=$ light red; $\mathrm{R}=$ red.

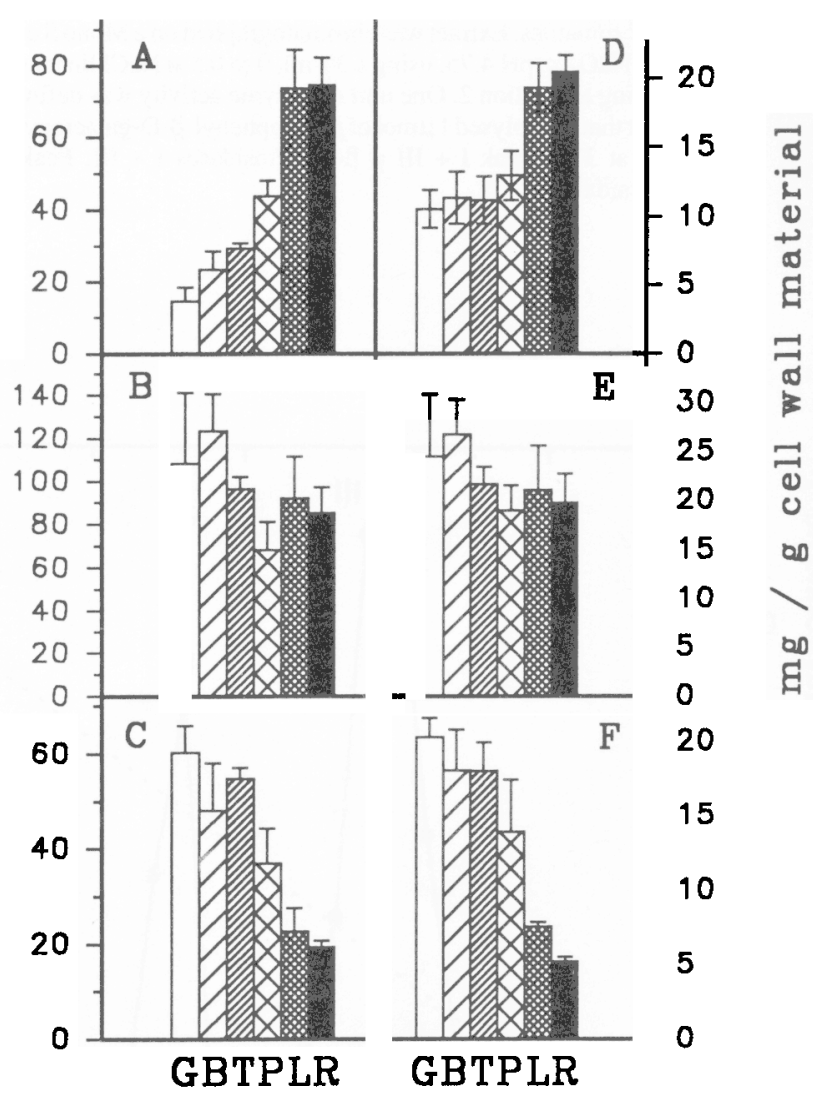

Fig. 3. Quantities of uronide (A-C) and neutral carbohydrate (D-F) solubilized from cell walls of 'Rutgers' tomatoes at six ripeness stages by water (A and $\mathbf{D})$, $0.05 \mathrm{M} \mathrm{CDTA}(\mathbf{B}$ and $\mathbf{E})$, and $0.1 \mathrm{M} \mathrm{Na}_{2} \mathrm{CO}_{3}(\mathbf{C}$ and $\mathbf{F})$. Mean of three replicates \pm SD. $\mathrm{G}=$ mature green; $\mathrm{B}=$ breaker; $\mathrm{T}=$ turning; $\mathrm{P}=$ pink; $\mathrm{L}=$ light red; $\mathrm{R}=$ red. 


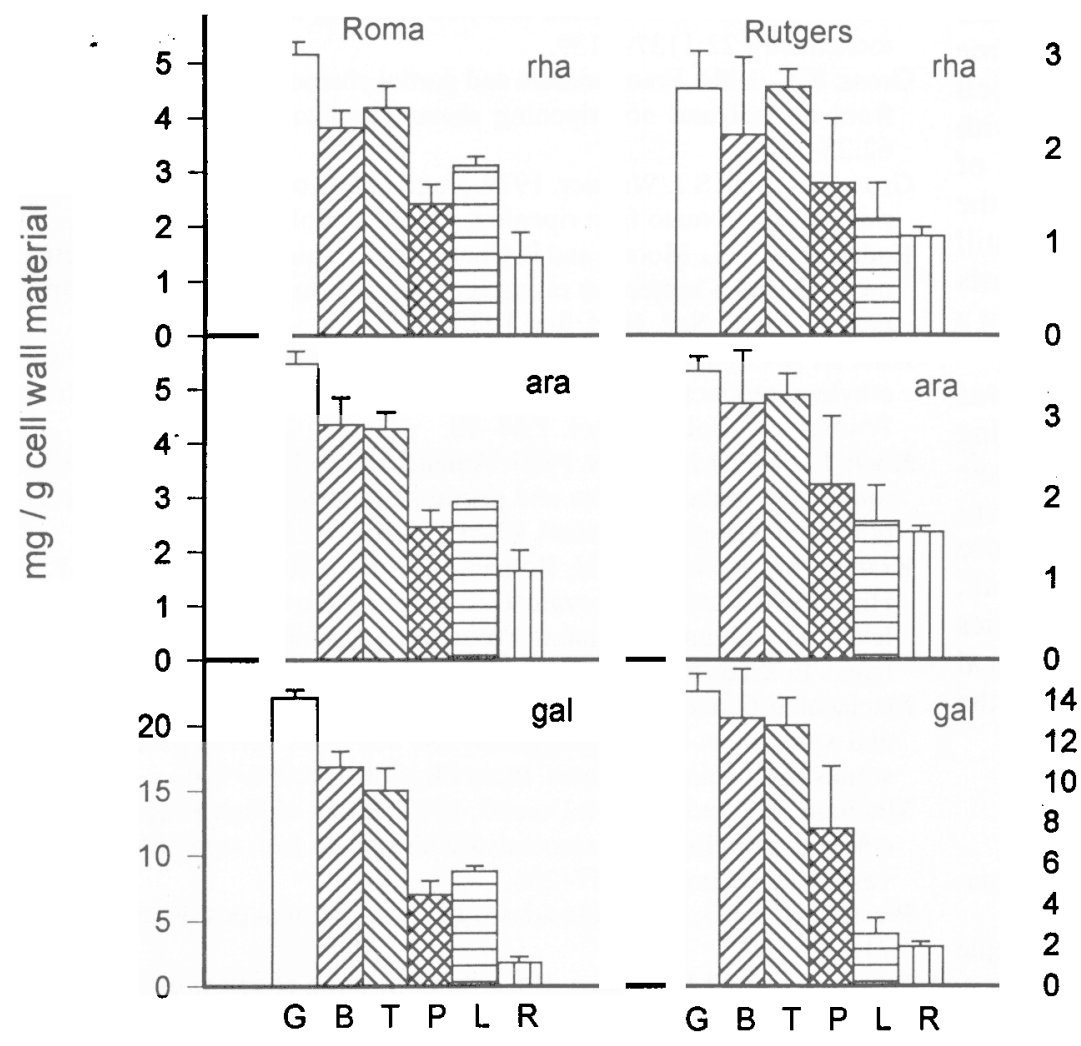

Fig. 4. Rhamnosyl, arabinosyl and galactosyl composition of $\mathrm{Na}_{2} \mathrm{CO}_{3}$-soluble pectin at six ripeness stages of 'Roma' and 'Rutgers' tomatoes. Mean of three replicates $\pm \mathrm{SD}$. $\mathrm{G}=$ mature green; $\mathrm{B}=$ breaker; $\mathrm{T}=$ turning $; \mathrm{P}=$ pink $; \mathrm{L}=$ light red $; \mathrm{R}=$ red.

FPLC cation-exchange separation was used here instead of the sequential chromatographic separations of the cited studies. Whatever the case, the levels of activity reported here for red fruit are comparable with those of the early study.

In fruit of both cultivars, a progressive increase in B-galactosidaseII activity occurred during ripening against a background of unchanging combined $\beta$-galactosidase I + III activity. This agrees with the results of Pressey (1983) and Carey et al. (1995). A difference in appearance of $\beta$-galactosidase II activity in the two cultivars was apparent, with 'Roma' fruit first showing detectable activity at the breaker stage and 'Rutgers' fruit at the turning stage (Table 1). If loss of galactose from the cell wall is catalyzed by B-galactosidase II, the lag in the appearance of this enzyme in 'Rutgers' fruit relative to 'Roma' fruit should be reflected in a similar delay in galactose loss from the cell wall. Indeed, NSP galactose showed a significant decline as early as the breaker stage in 'Roma' fruit, but this was delayed until the pink stage in 'Rutgers' fruit (Fig. 4). Likewise, NSP galactose declined by the

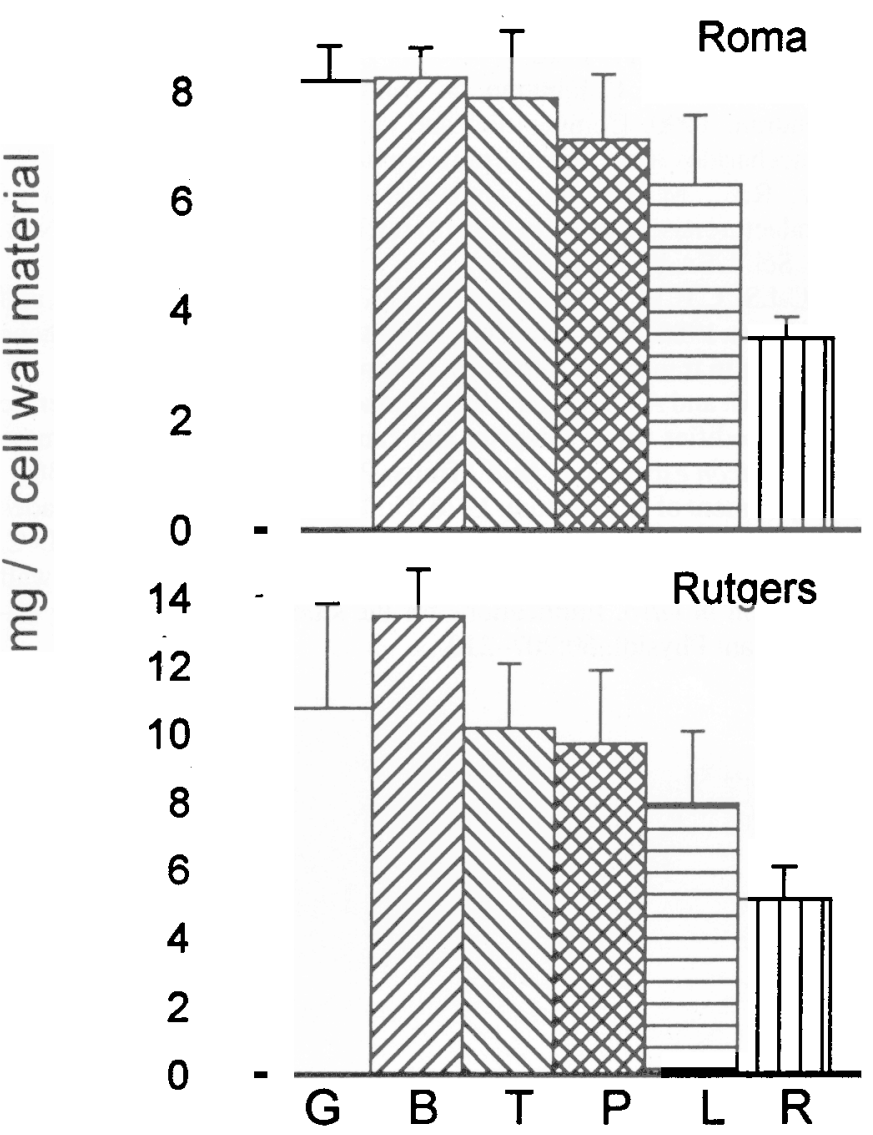

Fig. 5. Galactosyl composition of CDTA-soluble pectin at six ripeness stages of 'Roma' and 'Rutgers' tomatoes. Mean of three replicates \pm SD. $G=$ mature green; $\mathrm{B}=$ breaker; $\mathrm{T}=$ turning; $\mathrm{P}=$ pink, $\mathrm{L}=$ light red; $\mathrm{R}=$ red. red stage to $8 \%$ the level in green 'Roma' fruit compared to only a decline to $14 \%$ the level in green 'Rutgers' fruit (Fig. 4). This is compatible with the higher B-galactosidase II activity and more extended period of enzyme activity seen in 'Roma' relative to 'Rutgers' fruit (Table 1). The flaw in this correlation is that, while the expected delay between the cultivars is evident, the actual stage when B-galactosidase II is first seen and galactose loss is first evident do not coincide. One explanation for this discrepancy is that the ability to detect the galactose decline is hampered by the fact that part of the galactose lost from the NSP fraction is due to the PG solubilization of polyuronide with its associated rhamnose, arabinose and galactose constituents (Barrington et al., 1993). The galactose in this WSP fraction, so generated, is therefore irrelevant to $\beta$-galactosidase II action, and for this reason compositional analysis of WSP was not pursued. By comparison, the CSP fraction is better poised to address this issue, as it does show a loss of galactose but is apparently not a target for PG as no uronide (Figs. 2 and 3) or rhamnose (data not shown) decline occurred in this fraction. However, galactose loss in this fraction was minimal and appeared late (Fig. 5) in contrast to the NSP fraction, which seemed the main target for B-galactosidase II (Fig. 4). Kim et al. (1991) have previously shown that net galactose loss from the cell wall does not simply begin with ripening but occurs at a steady, slow rate throughout growth of the tomatoes, accelerating during ripening. The role of $\beta$-galactosidase II in this earlier phase of the fruit's development also requires study.

ß-Galactosidase II activity has been shown to increase during ripening, and the delayed appearance in one cultivar is reflected in a delayed NSP galactose loss in that same cultivar. Pressey (1983) and Carey et al. (1995) have shown that B-galactosidase II is an exe-acting hydrolase. Gross (1983) has also shown that free galactose accumulates in the flesh of ripening tomatoes, and this increase is not shown by the nonripening rin and Nor mutants. 
Taken together, these suggest that the substrate for B-galactosidase II is a NSP B-galactan and the product of this reaction is free galactose. Koch and Nevins (1989) have shown that tomato cell walls from increasingly later ripeness stages, treated in vitro with PG, generate polymeric fragments with decreasing amounts of galactose. This suggests that PG and $\beta$-galactosidase II target the same polymer in the wall, but the fact that galactose loss still proceeds in the absence of PG (Barrington et al., 1993) suggests that down-sizing and solubilization of this polymer by PG is not a necessary prerequisite for $\beta$-galactosidase II action.

In our study, softening began before $\beta$-galactosidase $\mathrm{H}$ was detected (Table 1), suggesting that the earliest phase of softening is orchestrated by some other enzyme or mechanism. Others have shown a good correlation between PG and tomato pericarp softening (Ahrens and Huber, 1990) despite the fact that anti sense attenuation of PG did not prevent fruit softening (Smith et al., 1988; Schuch et al., 1991). One explanation of these anomalies may be that fruit softening embodies several distinct biochemical processes. B-Galactosidase II and PG may be just two prongs of the coordinated attack launched on the cell wall during ripening.

\section{Literature Cited}

Ahrens, M.J. and D.J. Huber. 1990. Physiology and firmness determination of ripening tomato. Physiol. Plant. 78:8-14.

Blakeney, A.B., P.J. Harris, R.J. Henry, and B.A. Stone. 1983. A simple and rapid preparation of alditol acetates for monosaccharide analysis. Carbohyd. Res. 113:291-299.

Blumenkrantz, N. and G. Asboe-Hansem. 1973. New method for quantitative determination of uronic acids. Anal. Biochem. 54:484-489.

Brady, C.J. 1987. Fruit ripening. Annu. Rev. Plant Physiol. 38: 155-178. Carey, A.T., K. Holt, S. Picard, R. Wilde, G.A. Tucker, C.R. Bird, W. Schuch, and G. B. Seymour. 1995. Tomato exo-(1 -4)-ß-D-galactanase. Isolation, changes during ripening in normal and mutant fruit, and characterization of a related cDNA clone. Plant Physiol. 108:1099_ 1107.

Barrington, C.M.S., L.C. Greve, and J.M. Labavitch. 1993. Cell wall metabolism in ripening fruit. VI. Effect of the antisense polygalacturonase gene on cell wall changes accompanying ripening in transgenic tomatoes. Plant Physiol. 103:429-434.

Dische, Z. 1962. Color reactions of carbohydrates, p. 475-514. In R.L. Whistler and M.L. Wolfrom (eds.). Methods in carbohydrate chemistry. Academic Press, New York.

Fischer, R.L. and A.B. Bennett. 1991. Role of cell wall hydrolyses in fruit ripening. Annu. Rev. Plant Physiol. Plant Mol. Biol. 42:675-703.

Giovannoni, J.J., D. DellaPenna, A.B. Bennett, and R.L. Fischer. 1989. Expression of a chimeric polygalacturonase gene in transgenic rin (ripening inhibitor) tomato fruit results in polyuronide degradation but not fruit softening. Plant Cell 1:53-63.

Gross, K.C. 1983. Changes in free galactose, myo -inositol and other monosaccharides in normal and non-ripening mutant tomatoes. Photochemistry 22:1137-1139.

Gross, K.C. 1984. Fractionation and partial characterisation of cell walls from normal and non-ripening mutant tomato fruit. Physiol. Plant. 62:25-32.

Gross, K.C. and S.J. Wanner. 1979. Degradation of cell wall polysaccharides during tomato fruit ripening. Plant Physiol. 63:117-120

Kader, A.A., L.L. Morris, and P. Chen. 1978. Evaluation of two objective methods and a subjective rating scale for measuring tomato fruit firmness. J. Amer. Soc. Hort. Sci. 103:70-73.

Kim, J., K.C. Gross, and T. Solomos. 1991. Galactose metabolism and ethylene production during development and ripening of tomato fruit. Postharvest Biol. Technol. 1:67-80.

Koch, J.L. and D.J. Nevins. 1989. Tomato fruit cell wall. I. Use of purified tomato polygalacturonase and pectinmethylesterase to identify developmental changes in pectins. Plant Physiol. 91:816-822.

Kramer, M., R. Sanders, H. Bolkan, C. Waters, R.E. Sheehy, and W.R. Hiatt. 1992. Postharvest evaluation of transgenic tomatoes with reduced levels of polygalacturonase: Processing, firmness and disease resistance. Postharvest Biol. Technol. 1:241-255.

Maclachlan, G. and C. Brady. 1994. Endo-1,4-B-glucanase, xyloglucanase, and xyloglucan endo-transglycosylase activities versus potential substrates in ripening tomatoes. Plant Physiol. 105:965-974.

Mitcham, E.J. and R.E. McDonald. 1992. Effect of high temperature on cell wall modifications associated with tomato fruit ripening. Postharvest Biol. Technol. 1:257-264.

Pressey, R. 1983. ß-Galactosidases in ripening tomatoes. Plant Physiol. 71:132-135.

Pressey, R. and J.K. Avants. 1982. Solubilisation of cell walls by tomato polygalacturonases: Effects of pectinesterase. J Food Biochem. 6:5774.

Schuch, W., J. Kanczler, D. Robertson, G. Hobson, G. Tucker, D. Grierson, S. Bright, and C. Bird. 1991. Fruit quality characteristics of transgenic tomato fruit with altered polygalacturonase activity. HortScience 26:1517-1520.

Seymour, G.B., I.J. Colquhoun, S. DuPont, K.R. Parsley, and R.R. Selvendran. 1990. Composition and structural features of cell wall polysaccharides from tomato fruits. Photochemistry 29:725-731.

Sheehy, R.E., M. Kramer, and W.R. Hart. 1988. Reduction of polygalacturonase activity in tomato fruit by antisense RNA. Proc. Natl. Acad. Sci. USA 85:8805-8809.

Smith, C.J.S., C.F. Watson, J. Ray, C. R. Bird, P. C. Morns, W. Schuch, and D. Grierson. 1988. Anti sense RNA inhibition of polygalacturonase gene expression in transgenic tomatoes. Nature 334:724-726

Tieman, D.M. and A.K. Handa. 1994. Reduction in pectin methylesterase activity modifies tissue integrity and cation levels in ripening tomato (Lycopersicon esculentum Mill.) fruits. Plant Physiol. 106:429-436.

U.S. Department of Agriculture. 1976. United States standards for grades of fresh tomatoes. Agr. Mkt. Serv., U.S. Dept. of Agr., Washington, D.C. Wanner, S.J. and H.L. Bloom. 1977. Characteristics of tomato cell wall degradation in vitro. Implications for the study of fruit-softening enzymes. Plant Physiol. 60:207-210. 